\title{
Atenção à crise na contemporaneidade: desafios à Reforma Psiquiátrica Brasileira
}

\author{
Care for crisis in contemporaneity: challenges in the Brazilian \\ Psychiatric Reform
}

Volnei Antonio Dassoler' ${ }^{\mathbf{1}}$ Analice de Lima Palombini1

DOI: $10.1590 / 0103-11042020 E 323$

RESUMO Neste ensaio, são abordados os modos de viver e de acolher a experiência de crise no âmbito da saúde mental brasileira, considerando que esse acontecimento se impõe como um dos desafios estratégicos da fase atual da atenção psicossocial. Essa demanda heterogênea evidencia os efeitos coletivos e individuais decorrentes das transformações da vida contemporânea no mundo ocidental, cenário que, no contexto brasileiro, envolve, com frequência, crescentes situações associadas a rupturas e violências. Além disso, o acolhimento à crise e a clínica da urgência ainda se apresentam fortemente marcados pelo discurso psiquiátrico, que mantém legitimidade exclusiva nesse âmbito ao fornecer uma interpretação para a crise como evidência de uma psicopatologia. Em contrapartida, propõe-se uma noção de crise referida a um momento específico da existência, o qual condensa e atualiza uma série de afetos e impasses próprios à heterogeneidade que faz parte da vida. Nesse sentido, recupera-se a dimensão simbólica que intervém nesse acontecimento, privilegiando-a como recurso de subjetivação e tratamento para as modalidades de cuidado que se contrapõem à lógica discursiva psiquiátrica.

PALAVRAS-CHAVE Atenção psicossocial. Intervenção na crise. Acolhimento. Saúde mental.

\begin{abstract}
In this essay, we address the ways of approaching and embracing the experience of crisis within the scope of Brazilian mental health, considering that this event is one of the strategic challenges to the current phase of psychosocial care. This heterogeneous demand stems from the suffering produced by the collective and individual effects due to the changes of contemporary life in the Western world, considering that the Brazilian scenario increasingly involves situations associated with ruptures and violence. Due to such characteristics, the embracement of crisis and urgent clinical assistance are still strongly marked by the psychiatric discourse, which is acknowledged and demanded as having exclusive legitimacy in such scenario, interpreting crisis as an evidence of psychopathology. We, however, propose a notion of crisis that refers to a specific moment in existence and that condenses and updates a series of affections and impasses related to the heterogeneity of factors that are part of life. In this sense, we regain the symbolic dimension that intervenes in that event and privilege it as a resource for accessing the subject and the different modalities of care that oppose the psychiatric discursive logic.
\end{abstract}

KEYWORDS Psychosocial care. Crisis intervention. User embracement. Mental health.

1 Universidade Federal do Rio Grande do Sul (UFRGS) - Porto Alegre (RS), Brasil. dassoler@terra.com.br 


\section{Introdução}

Dentre os vários desafios que concernem ao curso atual da Reforma Psiquiátrica Brasileira (RPB), os modos de cuidado diante da experiência subjetiva de crise e o seu correlato clínico de urgência se sobressaem. A necessidade de um marco legal e político que respaldasse um modelo substitutivo à lógica manicomial, comprometido com a crítica às capturas discursivas e ao mecanismo de exclusão a que a loucura esteve submetida desde a modernidade, fez com que o interesse inicial do movimento se dirigisse, prioritariamente, aos usuários com transtornos mentais graves e com histórico de longos períodos de internação em instituições asilares e excludentes.

Hoje em dia, apesar de alguns retrocessos, não restam dúvidas quanto às conquistas alcançadas nesse processo de transformação que veio com a substituição do modelo manicomial para o modelo de atenção psicossocial, formalizado pela Lei ${ }^{\circ} 10.216 / 2001^{1}$. Orientada pelo cuidado em liberdade, pela garantia dos direitos humanos e civis, pela afirmação da participação do usuário em seu projeto terapêutico e pela implosão da noção da loucura como expressão de doença mental, criou-se a Rede de Atenção Psicossocial (Raps), por meio de um conjunto de dispositivos espalhados pelo País, em especial, o Centro de Atenção Psicossocial (Caps).

Esse processo, de características multifacetadas, teve inspiração no modelo do Sistema Único de Saúde (SUS), desenhando diretrizes e princípios para a nascente atenção psicossocial, com serviços organizados em rede, de caráter territorial e interdisciplinar. Como é sabido, no cenário dinâmico das políticas públicas, os impasses se renovam, deslocam-se e introduzem novos desafios. Assim, em um primeiro momento, a reforma esteve comprometida com a problematização da visão dominante sobre a loucura e com o estabelecimento de um acordo político e jurídico que interviesse objetivamente na formulação dos modos de tratamento. Em suma, o objetivo da reforma não se restringia unicamente à reorganização dos fluxos e dos serviços, mas visava, radicalmente, interrogar o domínio do pensamento psiquiátrico e as consequências subjetivas e culturais dessa forma de compreensão da loucura. Com efeito, os esforços iniciais foram direcionados à população com transtornos graves que estava submetida ao domínio da lógica psiquiátrica que lhe atribuía características de periculosidade, incapacidade civil e inevitável exclusão social.

Na sequência, o movimento reformista se ocupou com as questões do campo problemático das drogas, que emergiram fortemente no final dos anos 1990 no Brasil. Atento às diretrizes psicossociais, implementaram-se novos arranjos organizacionais, como os Centros de Atenção Psicossocial Álcool e outras Drogas (Caps AD), e estratégias de cuidado ampliado, como redução de danos e consultório na rua, que permitiram o protagonismo do usuário - mesmo em situação de vulnerabilidade - no seu projeto terapêutico. Outra demanda que recebeu atenção por parte das políticas públicas envolveu os transtornos graves no desenvolvimento da infância e adolescência. Nesse caso, reconheceu-se que o segmento apresenta especificidades que não são contempladas na mesma medida da referência ao universo adulto. Essa variação exige, por parte das equipes, um intenso trabalho intersetorial, sendo uma das justificativas para a proposição de um modelo assistencial dirigido a esta população: Centro de Atenção Psicossocial Infantojuvenil (Capsi).

Como se pode concluir, a atenção psicossocial é um terreno dinâmico, atravessado pela atualidade e permeável às influências advindas do campo social e político, em um jogo permanente de forças e tensões. De fato, entendemos que o acolhimento à crise é um tema que, até recentemente, teve sua importância secundarizada no conjunto das ações do novo modelo de cuidado. Atualmente, o 
tema emerge como pauta urgente requisitando especificação, investimento e delimitação quanto à responsabilidade de cada componente da rede de atenção em relação ao acolhimento à crise para usuários com transtornos graves e para aqueles que atravessam alguma experiência aguda de sofrimento psíquico sem um histórico pregresso de sofrimento psíquico.

A designação de pessoa com transtorno mental aparece referida na Lei ${ }^{0} 10.216$, que trata da proteção e dos direitos desse indivíduo e do redirecionamento do modelo assistencial em saúde mental. Pouco tempo depois, a Portaria n ${ }^{0} 336 / 2002^{2}$, que estabelece os Caps e suas modalidades, já aparece incorporando os complementos 'grave/severo e persistente'. De maneira geral, essa designação especifica um segmento de usuários cujas características e necessidades de maior complexidade irão requerer suporte psicossocial mais abrangente. Tal quadro está associado a duração dos problemas, intensidade do sofrimento, extensão das dificuldades e incapacidades nas relações interpessoais, nas competências sociais; e, por fim, inclui o diagnóstico psiquiátrico ${ }^{3}$.

Cotidianamente, o acolhimento do usuário em crise é uma prática que pode acontecer tanto nas Unidades Básicas de Saúde (UBS), com possibilidade de encaminhamento às unidades especializadas, quanto, diretamente, nos serviços de urgência geral e/ou psiquiátricas localizados em instituições hospitalares. Em tese, esses dois planos de cuidado funcionam por meio da identificação e da tradução do sofrimento subjetivo em doença/transtorno, herdeiros da compreensão biomédica do sofrimento mental. Essa realidade favorece a inscrição do código psiquiátrico como campo de significação à crise, com ênfase, quase exclusiva, ao seu viés negativo. Nesse sentido, as abordagens tradicionais tendem a separá-la do conjunto da vida do sujeito, priorizando medidas clínicas de contenção medicamentosa, nova versão do poder psiquiátrico que compôs o processo histórico de constituição da psiquiatria como ciência médica 4 . Nessa lógica, a retomada da palavra e o caráter terapêutico da produção narrativa são pouco valorizados, fato que decorre, entre outros motivos, pela redução da complexidade dessa vivência à nuança de perigo, perda de controle e evidência aguda de uma psicopatologia 5 . Essa face atualizada da psiquiatria avançou o novo século no País, penetrando o contexto da saúde mental. Assim, gradativamente, as práticas baseadas na palavra teriam perdido espaço e valor em favor da prescrição generalizada de medicação ${ }^{6}$. A popularização da psicofarmacologia é respaldada pelo seu efeito imediato e por ser, de alguma maneira, acessível à população, circunstâncias que resultam no descrédito dos dispositivos clínicos regidos pela escuta e pela palavra.

Com este ensaio, queremos ressaltar a presença cada vez mais constante nos serviços de saúde da atenção básica, de manifestações de crise associadas a fenômenos de violência, incluindo acontecimentos de potencialidade traumática, de natureza sexual e doméstica, de ideações e tentativas de suicídio, além da agudização de quadros depressivos e de ansiedade. Cabe ressaltar que parte significativa dessa população não apresenta histórico pregresso de acesso à rede por esse motivo. Além disso, quando necessário, encontra dificuldades de identificar, nos atuais equipamentos da Raps, a quais serviços deve e pode recorrer com a garantia de acolhimento. Esse cenário torna os temas da crise e da urgência relevantes na atualização das políticas públicas de saúde mental, pelo reconhecimento das dificuldades e dos mal-entendidos acerca da responsabilidade dos serviços e do manejo clínico que requerem. Nesse sentido, o ensaio problematiza o lugar que a crise e a urgência ocupam no ideário reformista e no cotidiano da Raps e o modo como as situamos em relação ao avanço do processo de medicalização da sociedade com o consequente esvaziamento do registro simbólico como recurso de tratamento. 
Para tanto, em nosso ensaio, faremos um percurso teórico-clínico que inclui uma análise crítica acerca das especificidades da experiência aguda do sofrimento psíquico no campo da atenção psicossocial, com base em conceitos oriundos da psicanálise freudo-lacaniana. A apresentação de vinhetas clínicas aparece, no texto, como um elemento adicional de respaldo a nossa argumentação que nos ajuda a introduzir e sugerir alguns princípios básicos pertinentes à intervenção à crise.

\section{O esvaziamento $\mathrm{e}$ a precarização do registro simbólico na contemporaneidade e suas consequências na saúde mental}

Segundo o dicionário eletrônico Houaiss 7 , o substantivo crise deriva do latim crisis, que sugere algo relativo a um momento de decisão e de mudança, e do grego Krisi, que atribui sentido para uma ação ou para a faculdade de distinguir, decidir, separar e julgar. Por extensão, conclui-se que o conceito de crise comporta, paradoxalmente, a qualidade de risco e perigo e, simultaneamente, faz referência a uma oportunidade que se coloca ao sujeito, com potência de transformação. De modo geral, no entanto, a dimensão do sofrimento e de risco se sobrepõe pela intensidade de angústia que a acompanha. $\mathrm{O}$ aspecto de transformação que lhe é vinculado nem sempre consegue ser reconhecido e, quando isso ocorre, costuma ser em um momento posterior à experiência aguda, como parte de um novo processo que desvela e decompõe as diversas dimensões da subjetividade que participaram da sua emergência

A disseminação da palavra crise, a partir do final do século XX e início do XXI, testemunha uma difusão sem precedentes do seu uso na história humana, aparecendo associada a contextos diversos como saúde, política, economia, ecologia, religião. Em um panorama mais amplo, não restam dúvidas de que vivemos um período histórico e social que descreve mutações de toda ordem em torno de paradigmas centrais do nosso tempo, submetendo a perspectiva subjetiva ao exame das circunstâncias históricas. O significante 'crise' ganha centralidade nas narrativas que se produzem no atual estágio da modernidade - temporalidade histórico-social afetada pelas consequências do processo de globalização, como a introdução maciça de novas tecnologias de informação e de comunicação, a transformação das relações de trabalho e de convívio e a ascensão do discurso científico, e pela constatação de que vivemos em um ambiente novo, sem precedentes para as atividades da vida individual, o qual pode ser caracterizado como um 'viveiro de incertezas'8. Com efeito, os laços inter-humanos - que teciam uma rede de proteção e segurança para a qual era digno o investimento de tempo e esforço - transformaram-se em modos frágeis e temporários de cuidado em um ambiente de incertezas no espaço social. A vida se converteu, fundamentalmente, em um projeto individual orientado por escolhas cada vez mais distantes do interesse em participar e interferir na vida pública.

Por óbvio, sempre houve situações de crises subjetivas que emergem na dialética de continuidades e descontinuidades com o laço social. A civilização repousa, sob certa medida, na supressão de um tanto de pulsão e na renúncia de uma parcela do sentimento de onipotência e das inclinações agressivas ${ }^{9,10}$. Nessa hipótese, o sujeito não se constitui como entidade autônoma nem porta essência, afetado pela incidência do inconsciente e da linguagem que o institui como dividido. Efeito disso, tampouco é um sujeito a-histórico, retirado da natureza, marcado que é pelo pertencimento a uma ordem social e cultural.

Essa equação marca os fundamentos do pensamento e da prática analítica: perde-se um tanto de liberdade para obter um lugar de pertencimento e de proteção social, processo 
que resulta no mal-estar como 'invariante histórico' e 'elemento estrutural' '11 que, constitutivo do humano, na condição de ser falante, 'se inscreve sempre no campo da subjetividade'12. A irredutibilidade dessa condição não significa que se vive uma espécie de crise permanente. Contudo, em alguns momentos e por incontáveis circunstâncias, o sujeito se percebe despojado do enquadre imaginário que lhe dá um contorno de estabilidade à existência, efeito da precarização dos recursos simbólicos que sustentam a dimensão ficcional da vida, entendida como realidade psíquica. Acontecimentos com efeito disruptivo, como a exposição à violência ou o desencontro amoroso, podem ser suficientes para que a crise se apresente ao sujeito.

No atual campo da saúde, o mal-estar tende a ser capturado, privilegiadamente, a partir do referencial médico e de todas as disciplinas que gravitam em torno do discurso da ciência. Amparado na leitura extensa que Foucault faz do tema da medicina e de seus efeitos civilizatórios, Birman ${ }^{13}$ entende que não existe possibilidade de pensar a modernidade sem a inclusão dessa categoria como marca constitutiva. Nessa nova ordem social, cria-se uma sociedade normativa que fará da medicina uma espécie de modelo antropológico cujo saber opera como fonte de regularização e normalização da vida. A migração do pensamento médico para a saúde mental o tornou dominante nas formações das ciências humanas e da saúde, determinando ativamente concepções e orientando intervenções e procedimentos técnicos. Uma das consequências dessa conjuntura é a desvalorização das práticas de cunho simbólico que se colocam em operação a partir da fala, como a psicanálise. Essa posição desautoriza o sujeito a buscar em sua história de vida os apoios e balizamentos necessários à travessia da existência, mesmo em situações de crise. Para fazer frente a isso, somos instigados a encontrar brechas que restabeleçam viabilidade e dignidade às modalidades de cuidado pertinentes ao campo psicossocial, amparadas no capital simbólico de que a psicanálise é tributária.

\section{$O$ cuidado à crise e à urgência no projeto brasileiro da atenção psicossocial}

De acordo com a Resolução $n^{0} 1.451 / 95$, o Conselho Federal de Medicina definiu como Urgência a ocorrência imprevista de agravo à saúde, de causa diversa, ocorrida em qualquer local e motivada por qualquer circunstância, cujo portador requer assistência médica imediata com vistas a reduzir eventual risco potencial de morte. A Emergência, por sua vez, seria a constatação médica de condições de agravo à saúde que implicam risco iminente de vida ou sofrimento intenso, exigindo, portanto, o tratamento médico imediato pela constatação da gravidade do quadro em observação ${ }^{\mathbf{1 4}}$. Sem avançar em maiores tipificações, ambas têm em comum a pressa no cumprimento de protocolos e de procedimentos.

Nessa conjuntura, a emergência, desde o ponto de vista psiquiátrico, caracterizar-se-ia como a manifestação de um distúrbio de pensamento, emoção ou comportamento, a partir da qual o atendimento médico se faz necessário para reduzir maiores comprometimentos à saúde psíquica, física e social e eliminar possíveis riscos à vida da pessoa ou à de terceiros ${ }^{15}$. Com efeito, esse diagnóstico compreende a alteração psicológica aguda (pânico, crise de angústia, depressão) e possível quadro de desorganização comportamental (surto psicótico) que põem em risco eventual o paciente e seu entorno ${ }^{16}$. Essa contextualização tipifica o conjunto de ocorrências envolvendo pessoas com histórico de transtorno psiquiátrico grave e contínuo e, também, aquelas em episódio agudo sem sofrimento persistente.

A partir desse cenário, como podemos caracterizar a passagem da noção de crise e de urgência médica para sua especificação no âmbito da atenção psicossocial levando em conta seus princípios, a complexidade desse fenômeno e a construção de práticas articuladas com as possibilidades do dia a dia dos 
profissionais, dos recursos e dos serviços de saúde? A abordagem preconizada pela clínica médica encontra limitações ao ser confrontada pela afirmação da subjetividade como interface imprescindível da saúde mental ${ }^{\mathbf{1 7}}$. Dessa forma, quando reconhecida, a noção de subjetividade redimensiona tanto a concepção e o diagnóstico de crise quanto o objetivo e a direção clínica a serem estabelecidos.

Em um primeiro tempo, a abordagem inicial à crise, seja no domínio médico, seja no campo ampliado da saúde mental, congrega uma perspectiva terapêutica comum: a necessidade de uma ação imediata, motivada pela constatação de sofrimento agudo que excede às condições psíquicas e sociais que o sujeito tem à sua disposição. É preciso intervir, sem demora. Entretanto, em um segundo tempo, parte desse mesmo acolhimento, impõe-se uma diferença crucial no manejo do tempo enquanto estratégia clínica. Nesse momento, as intervenções se colocam em direções opostas. Se, para o campo médico e psiquiátrico, a pressa é um índice que orienta as avaliações e as decisões, na saúde mental, o alargamento do tempo surge como premissa clínica fundamental de tratamento. Nesse último caso, a pausa se oferece como diretriz necessária ao advento do sujeito e das condições de elaboração psíquica daquilo que está suposto como pano de fundo da crise.

Com efeito, nesse caso, a torção no manejo do tempo introduz uma pausa onde havia pressa, conduta que abre espaço à narrativa e à subjetividade. Fica claro que a pausa, segundo tempo do acolhimento, configura-se como manobra terapêutica por meio da introdução da palavra e com o propósito de recuperar e revalidar a eficácia do repertório simbólico ${ }^{\mathbf{1 8}}$.

É neste ponto que a discussão sobre a eficácia simbólica entra em cena, tensionando o domínio das categorias diagnósticas psicopatológicas e o recurso psicofarmacológico como elementos organizadores de um saber que se pretende hegemônico na interpretação e no tratamento do sofrimento psíquico. Isso significa reconhecer que a insígnia diagnóstica, que advém do campo psiquiátrico legitimado pelo discurso da ciência, não pode ser a única representante nas formas de acolher e tratar nesse âmbito.

A problematização sobre os modos de abordagem à crise é imprescindível no atual estágio da RPB, para que ela não se resuma à mera conversão psicopatológica, conduta que desimplicaria os demais profissionais/atores quanto à competência e à responsabilidade de sustentar práticas ampliadas e condizentes com as diretrizes da atenção psicossocial nesse contexto, a própria equipe é afetada em seus paradigmas, princípios e intervenções ${ }^{19}$. Assim, tão importante quanto um trabalho com o sujeito, é o trabalho com a equipe, visando à problematização ética e clínica dos discursos hegemônicos e à incorporação de novos campos de conhecimento e de práticas a partir dos recursos de que o serviço dispõe.

Em termos gerais, até recentemente, o debate sobre as particularidades da intervenção na crise não era expressivo na saúde mental e, quando ocorria, fazia-se em torno dos quadros considerados graves. Apesar do nível crescente de interesse suscitado muitas vezes pelos casos manifestos de crise, é surpreendente não encontrar muitos estudos e pesquisas em relação ao que chamamos de clínica da urgência ${ }^{20}$. Paradoxalmente, $\mathrm{o}$ atendimento à crise é considerado nevrálgico para a sustentação do processo reformista, na medida em que haveria dificuldades em sustentar avanços sem se ocupar da garantia desse cuidado nos diferentes pontos da rede, de acordo com a avaliação da gravidade da situação ${ }^{21}$. Admite-se que os setores responsáveis pelo atendimento à crise continuam sendo os menos permeáveis às transformações realizadas nas políticas públicas de saúde mental desde a década de 1980. Nesse sentido, o seu funcionamento conserva o modelo operacional padronizado dos tradicionais Serviços de Emergências Psiquiátricas (SEP), cujo enquadre opera pela exclusão da condição de responsabilidade do sujeito, caracterizando-se por serem essencialmente especializados, hierarquizados e dissociados dos demais serviços em rede 22 . 
Assim, a formulação de respostas à crise é uma condição para o prosseguimento das mudanças e da manutenção do ideário reformista ${ }^{23}$. Respostas à crise funcionam como analisadores dos processos implementados pela Reforma, uma vez que as dificuldades enfrentadas por muitos serviços indicam a permanência dominante da referência psiquiátrica nessa seara. $\mathrm{O}$ tema da crise também foi destaque no Relatório Final da IV Conferência Nacional de Saúde Mental Intersetorial, realizada em Brasília no ano de 2010:

A consolidação da reforma psiquiátrica exige a priorização, por parte dos gestores dos níveis federal, estadual e municipal, da atenção à crise no âmbito da rede substitutiva em saúde mental, considerando sua importância fundamental na implementação de processo efetivo que possibilite a extinção dos hospitais psiquiátricos e de quaisquer outros estabelecimentos

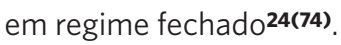

Temos, portanto, o registro da atualidade política e clínica dessa discussão. Cabe a ressalva de que a preocupação acima referida faz alusão às situações de crise no contexto dos usuários de transtornos graves que, até a década de 1980, tinham nas emergências dos manicômios o principal acesso ao circuito tradicional de internação ${ }^{25}$. Contudo, e uma vez mais, queremos reafirmar a existência de outra parcela da população que não corresponde à descrição acima, mas que se encontra propensa a vivenciar fenômenos agudos de sofrimento psíquico. Trata-se de um segmento que busca tratamento por força de algum acontecimento imprevisto ou, por outro lado, decorrente do agravamento de uma situação prévia que evoluiu para um nível insustentável.

$\mathrm{O}$ atendimento à crise sem relação com o contexto da loucura não é algo novo, no sentido de supor sua inexistência no passado. O que suscita interesse renovado diz respeito às proporções que essa demanda tem adquirido no cotidiano institucional da rede de saúde formal. Não seria demasiado dizer que os usuários que buscam tratamento situam-se cada vez menos como doentes mentais e cada vez mais como pessoas em crise. Isso traria novos desafios para a saúde mental, tanto para a instituição psiquiátrica, que surgiu em torno da doença mental e não foi organizada em torno da crise, quanto, sugerimos nós, para os serviços que fazem parte da realidade psicossocial brasileira ${ }^{26}$. Dito de outra forma, a esquizofrenia, a paranoia e a psicose seguem aparecendo, assim como as modalidades da neurose grave. Entretanto, cada vez mais a prática cotidiana aponta o incremento de uma demanda que se manifesta como insuportável ao sujeito comum e o impulsiona na busca de atendimento.

\section{Da crise à urgência: apontamentos clínicos}

A crise pode ser entendida como uma experiência de afetos, memórias, medos, angústias e anseios condensados em um determinado momento da existência, acompanhada de intenso sofrimento que ameaça a preservação das condições e das funções psíquicas. O termo é geralmente utilizado no campo da saúde mental para se referir a

[...] um momento individual específico, no qual efervescem questões, afetos, gestos e comportamentos variáveis e singulares, que afetam em graus variáveis a vida cotidiana da própria pessoa e daqueles de seu convívio e costumam ser determinantes das demandas e intervenções em serviços de Saúde Menta|27(96).

Em determinadas circunstâncias, o sujeito não consegue responder às demandas da vida com os próprios recursos psíquicos, com a rede de apoio e com o suporte das suas crenças e convicções. Nessa condição de fragilidade, a dimensão do sentido vacila e pode deixar de operar. Aos poucos, o sujeito se percebe em uma posição alheia àquilo que compõe sua existência, abrindo margem para o desejo de 
romper com o laço social. Nesse ponto, a crise pode assumir a prerrogativa de urgência, pela possibilidade efetiva de ruptura com o laço social por meio de condutas de autoagressão (suicídio), de violência dirigida a outros, de isolamento social extremo por meio do abandono de atividades cotidianas como trabalho e estudo. Como consequência, produz-se uma interferência radical na relação com o campo social, exigindo ${ }^{\mathbf{2 8}}$ uma intervenção que não pode ser adiada por colocar em jogo os limites de significação e de elaboração. Tal circunstância pressiona o sujeito e traz a possibilidade de que a solução se faça pela via do ato, o que deixa evidente que a crise comporta um viés que convoca o laço social.

São casos associados à problemática suicida e ao contexto de trauma. Esses marcadores denotam o caráter de urgência que algumas situações podem alcançar, consequência do fato do sujeito deixar de contar "com um discurso que opere para entender e lidar com o sofrimento"29(36). Defrontado com o limite do Outro da linguagem, enquanto função de escora para fazer laço social, o sujeito vai encontrar dificuldades de representar-se e de manter alguma liberdade diante da manifestação do Outro do gozo mortífero. Nesses casos, a crise é vivida como insuportável, evidenciada pela perda de sentido, efeito de um excesso pulsional que faz vacilar o sistema de representação ao ultrapassar as condições disponíveis daquilo que é possível ao sujeito significar ${ }^{30}$.

No caso de sujeitos sem histórico de sofrimento grave, estas situações podem ser traduzidas como efeito da desestabilização das referências simbólicas e imaginárias que ofereciam alguma proteção de sentido. Em seu lugar, produzem-se a incerteza e a insegurança, consequências da precarização dos esquemas interpretativos prévios, o que leva a um tipo de demanda marcada pela temporalidade da urgência. Em contrapartida, é desde o próprio registro simbólico que devemos buscar as condições para intervir na crise e na urgência, posição discursiva que se faz a partir da inclusão e da mediação de um semelhante, que pode ser assumido pelos profissionais da rede de saúde. Do ponto de vista clínico, esse caráter radical de alteridade assume uma função terapêutica ao oferecer e alternar as perspectivas de semelhança e de diferença como lugares ativos, vivos e compartilhados, que implicam e engajam o sujeito em seu sofrimento. Em outras palavras, esse outro, enquanto semelhante encarnado pelos profissionais da saúde, intervém pela mediação da linguagem, recuperando as possibilidades de significação e abrindo brechas para que outras formas de expressão possam emergir naquilo que é vivido como crise. Com efeito, a identificação e a atribuição do caráter de urgência a uma determinada experiência de sofrimento incluem fatores do próprio sujeito, do contexto em que ele vive e do serviço que é demandado. Dito de outra forma, o parâmetro que descreve a passagem da crise para a urgência não está dado nem objetivamente nem previamente, estando atrelado ao limite subjetivo, aos suportes sociais a que ele pode ter acesso e às noções de crise e de urgência com que cada serviço opera.

Essas situações-limite descrevem um estado de desamparo discursivo e caracterizam a chegada dos sujeitos ao acolhimento, vislumbrando, no serviço e na equipe, condições imaginárias e simbólicas possíveis para a retomada de um lugar de fala e de elaboração que pode recolocá-lo em outra relação com o que lhe produz urgência. Nessa linha de raciocínio, entende-se que a consulta de urgência em saúde mental é aquela que se realiza sem agendamento prévio, sendo qualificada como tal por quem procura o atendimento (usuário ou acompanhante), por considerar que o padecimento requer atenção imediata, vinculado ou não à concordância dos profissionais ${ }^{31}$. É a partir da chegada e do acolhimento que a dimensão clínica se abre, orientada pela ética de tratar o real pelo simbólico. Contudo, nem sempre essa é uma tarefa fácil de cumprir, seja porque o sujeito está premido pela angústia a ponto de não conseguir formular com clareza uma 
demanda, seja porque recusa o atendimento. Assim, para produzir pausa por meio da mediação simbólica, será necessário introduzir, deslocar e intervir no ritmo da urgência.

As possibilidades de cuidado à crise supõem que a dimensão de escuta tenha estatuto de ato, quer dizer, seja uma intervenção que coloque borda onde havia desamparo e ofereça uma localização ao sujeito que lhe possibilite formalizar algum tipo de elaboração sobre seu sofrimento onde antes havia uma suspensão temporária das condições de subjetivação. Se a urgência se caracteriza quando o tempo falta, é desde aí que o simbólico se apresenta como pausa, recurso terapêutico estratégico visando à apropriação da angústia e sua transformação em sintoma pela produção narrativa de contornos simbólicos ao real.

\section{Atualidade e especificidade da atenção à crise na atenção psicossocial}

Em geral, o campo da saúde não costuma ser a primeira escolha de um sujeito em sofrimento psíquico, mesmo em uma condição de crise. Normalmente, as pessoas transitam por vias que lhes são culturalmente familiares e facilmente acessíveis, ainda que antagônicas em suas éticas. É durante esse itinerário que os equipamentos de saúde podem ser acionados pelo usuário, sem que ele mantenha uma hierarquia rígida e definitiva entre as estratégias. Para o sujeito em sofrimento, não há contradição no fato de seu tratamento em saúde mental ser composto, simultaneamente, por intervenções de várias abordagens, desde aquelas com estatuto científico até as associadas a práticas leigas.

A aproximação entre crise e urgência é um desdobramento que ocorre regularmente, na medida em que a identificação de risco é comum e determinante para a passagem de uma para outra. Essa compreensão não é unânime no contexto brasileiro, campo pleno de contradições. Delineiam-se disputas técnicas e políticas que também se evidenciam na diversidade de concepções e modos de acolher à crise nos diferentes pontos da Raps, como UBS, Caps, Estratégias Saúde da Família (ESF), Unidade de Pronto Atendimento (UPA), Serviço de Atendimento Móvel de Urgência (Samu).

Coerente com esse direcionamento, podemos perguntar: por que parece que, para muitas equipes da atenção básica, a demanda de cuidado à crise é necessariamente mais bem atendida em um ambiente hospitalar e quais são os motivos e critérios determinantes para que o encaminhamento seja feito a um serviço especializado ou ao psiquiatra? O limite operacional do serviço e dos profissionais? A inexistência de recursos apropriados como medicação? A necessidade de uma escuta especializada? A constatação de risco e de perigo associados à demanda? Uma necessidade de tempo que não se encontra disponível, sem o qual o acolhimento não se sustenta?

Essas perguntas são fundamentais e precisam ser recolocadas às equipes multiprofissionais, seja no âmbito especializado, seja na atenção primária. É provável que, hoje, muitas das condutas estabelecidas encontrem-se naturalizadas de tal maneira que o atendimento inicial se resuma a um encontro protocolar, desconsiderando - de forma premeditada ou não - a singularidade do sujeito e de sua história. O fato é que muito da hegemonia psiquiátrica que ainda resta na atenção psicossocial é concedida pelas equipes, incautas de outros modos de acolher à crise ou inseguras em introduzir e intervir a partir de um outro paradigma. Além disso, o caráter difuso que caracteriza estruturalmente essa demanda é, muitas vezes, interpretado de forma ambivalente, e o sofrimento pode ficar marcado, ou pelo descrédito, ou pela identificação à angústia e ao desamparo do usuário, com inevitável efeito iatrogênico. Particularmente, essa situação favorece a ampliação do discurso biomédico, em especial, por meio da prescrição de ansiolíticos e de antidepressivos, de tal maneira que a rede básica de saúde é um dos 
principais responsáveis pelo aumento significativo de prescrições desses medicamentos em nosso país ${ }^{32}$.

Nesse cenário, identificamos um vácuo na Raps em relação a dispositivos clínico-institucionais capazes de contemplar um segmento populacional que pode, de forma contingente, atravessar uma situação de crise. Especificamente, com relação ao Caps, dispositivo central na política de saúde mental, embora o acolhimento à crise esteja previsto entre as suas funções terapêuticas, o cuidado é restrito aos usuários já vinculados ao serviço ou, se destinado a novos, alcança apenas aqueles que têm a descrição do sofrimento previsto em uma definição específica. Portanto, a necessária delimitação do público-alvo para cada modalidade de Caps inclui muitos, mas deixa de fora outros tantos. Este é o ponto para o qual gostaríamos de chamar a atenção: a existência de usuários que se encontram à deriva na Raps. São casos que não conseguem ser acolhidos nos Caps nem contemplados adequadamente na atenção básica.

A mãe de um jovem que havia morrido no incêndio na Boate Kiss foi levada por outro filho para o serviço de atenção psicossocial. Foi acolhida por uma profissional que avaliou a existência de um risco grave de suicídio. Preocupada, a psicóloga chamou a equipe para transmitir o recado da mulher de que não deveríamos nos sentir culpados pelo ato. Um novo colega se dispôs a conversar; e, quando chega à sala, ela se dirige a ele e diz que estava perdendo tempo, que seu ato já estava decidido, que não tinha nada para lhe falar, que já havia contado tudo para todo mundo: "Mas você não contou para mim, eu gostaria de saber", interveio o profissional. Demonstrando surpresa, a mulher baixa o tom de voz e começa a contar sua história. Ao final, faz-se a combinação de um contato por telefone no dia seguinte. Ela não se opôs, e foi o que fizeram, por alguns dias, antes de finalizar o acompanhamento a pedido dela.

Uma jovem de 18 anos foi levada pelos pais ao pronto atendimento após uma tentativa de suicídio feita a partir de cortes nos pulsos.
Ela deixou mensagens à família e aos amigos, desculpando-se pela decisão que teria sido motivada pelo término inesperado de um relacionamento amoroso. Foi medicada e diagnosticada com transtorno depressivo grave sem sintomas psicóticos e recebeu atestado para afastar-se do trabalho por quatro meses e procurar terapia. Após isso, foi encaminhada a quatro serviços diferentes, nos quais realizou novas entrevistas, em que se pediu que contasse novamente o que havia ocorrido para, enfim, na última consulta, receber a informação de que deveria aguardar em uma lista de espera.

Um jovem foi levado pela família para consultar na UBS porque, após uma briga na escola, começou a dizer que iria se matar. $\mathrm{Na}$ entrevista de acolhimento, queixou-se de que depois do que houve não se sentia bem na turma, apesar de reconhecer que ele mesmo provocou a briga. Ainda assim, dizia que, se o pai não tivesse vendido a arma, se mataria. A profissional que escutou o jovem conversou com a família e fez algumas orientações. O jovem veio uma vez mais na mesma semana e disse que ainda estava chateado, mas que havia passado a ideia de morrer.

Após a descoberta de uma traição, uma mulher ameaçou o marido de que iria se matar. Assustado, este tentou levá-la para atendimento na UBS, mas a esposa se recusou a ir ou a procurar psiquiatra ou psicólogo, e seguiu com as ameaças. O marido procurou informações na internet sobre como lidar com esses casos e chegou à conclusão da importância de falar com ela sobre o assunto e não a deixar sozinha. Entre culpado e preocupado, estabeleceu uma vigilância quase sem interrupção e uma insistência em falar sobre suicídio, fato que incrementou ainda mais a tensão entre ambos. Angustiado, procurou o serviço de atenção psicossocial e expôs a situação. De certa forma, percebeu que aderiu demasiada e acriticamente ao protocolo. Retornou uma vez mais, dizendo que seguia preocupado, mas que entendeu que a situação é complicada e que irão precisar de tempo para resolver a situação.

Após o incêndio na Boate Kiss, em Santa 
Maria, um dos jovens sobreviventes encerrou-se em seu quarto, no escuro, de onde só saía para pequenos afazeres, mantendo o mínimo de contato com alguns poucos amigos. Preocupados, estes sugeriram levá-lo para atendimento psiquiátrico e psicológico, sugestão que foi recusada. Diante disso, os colegas procuraram o serviço de acolhimento, criado para o cuidado às pessoas afetadas pelo incêndio, e, durante três semanas, foram acompanhados conjuntamente por dois profissionais, os quais se ocuparam com as angústias relativas ao amigo e também com aquelas que concerniam a cada um. Nenhum deles solicitou acompanhamento psicológico ou psiquiátrico.

Os fragmentos clínicos acima atestam uma vivência do sofrimento que deixa evidente a condição de desamparo subjetivo e discursivo que lança os sujeitos em um percurso errante. São momentos em que a fantasia, ou seja, a realidade psíquica parece ter sido suplantada pelo vazio ou pelo excesso - figurações da vivência do real, registro lacaniano para descrever a experiência de desamparo do sujeito quando lhe falta o sentido e ele se vê diminuído das condições de significação. Nesse sentido, o dispositivo de acolhimento visa "fazer passar o singular de cada urgência ao plano da fala"33(100). Trata-se, desde o primeiro momento, de tomar o acolhimento em um horizonte clínico, quer dizer, atribuir-lhe estatuto clínico, operação cujos efeitos incidem sobre a experiência subjetiva da urgência com vistas à sua singularização.

Os casos descritos acima portam traços que os singularizam em sua expressão, na forma como foram vividos e, também, na maneira como estabeleceram as respostas e as saídas, tanto em termos do que o serviço de saúde poderia propor quanto aquilo que caberia ao próprio sujeito. Acolher o sujeito em crise e estabelecer diretrizes na atenção psicossocial significam afirmar, fundamentalmente, que o próprio acolhimento é um dispositivo que porta função clínica por meio da oferta de um vínculo transferencial particular. $\mathrm{O}$ fato é que receber um sujeito em crise é uma intervenção que não pode ser submetida ao cumprimento protocolar voltado ao encaminhamento ou à avaliação psiquiátrica. Muitas vezes, orientadas pela pressa, as condutas precipitam conclusões que deixam de fora da hipótese diagnóstica e do projeto terapêutico elementos importantes da história do sujeito. Nesse sentido, o acolhimento tanto é o momento inicial, que pode ou não estabelecer confiança na rede de saúde criando vínculo, quanto é uma intervenção que produz, no seu próprio ato, efeitos terapêuticos importantes, em especial, nos casos de crise e urgência. Diante disso, condições subjetivas graves correm o risco de serem minimizadas, e situações menos complexas podem ser elevadas a graves e urgentes.

Uma premissa inicial nessa clínica passa por não responder à urgência do sujeito com a urgência do Outro, quer dizer, não intervir acuado pela demanda. Responder desde esse lugar favorece a instauração de condutas terapêuticas identificadas pela égide da massificação e da medicalização. A lógica desse acolhimento requer apostar em um tempo subjetivo que não se desencadeia se quem acolhe está apegado à sua própria angústia ou acomodado no lugar de sujeito suposto saber ${ }^{34}$. Ciente da singularidade de cada caso, trata-se de criar condições institucionais propícias a uma abertura discursiva que retire o sujeito do instante da perplexidade (instante de ver) e o coloque em causa, abrindo um tempo (cronológico e lógico) de compreender que possibilite sua circulação pelas determinações e indeterminações que se articulam nessa experiência subjetiva.

Por fim, consideramos que o cuidado à crise e à urgência dentro dos pontos de atenção que compõem a Raps poderia se beneficiar com a apropriação de alguns parâmetros como balizadores desse trabalho clínico sem, com isso, desconsiderar as possibilidades do sujeito e dos próprios serviços:

1. No campo da atenção à crise, as intervenções solicitam um dispêndio de tempo e energia diferenciado em comparação com as demandas convencionais, exigindo das equipes uma maior flexibilidade na construção de respostas; 
2. A crise é uma demanda que requer o acolhimento imediato, embora nem toda crise se qualifique como urgência;

3. A qualificação de urgência é uma prerrogativa que cabe, fundamentalmente, ao usuário e descreve uma experiência de caráter insuportável;

4. A pausa é um ato clínico que se introduz como estratégia clínica ante a temporalidade da pressa;

5. A pausa abre as condições para a fala, como aposta terapêutica no recurso simbólico com vista à retomada do fio narrativo;

6. A crise não equivale obrigatoriamente a um diagnóstico de transtorno, de forma que medicar pode ser uma parte do trabalho, mas não a sua síntese;

7. $\mathrm{O}$ acolhimento é um dispositivo eminentemente clínico e não se confunde com triagem nem é voltado a um encaminhamento;

8. Muitos usuários apresentam autonomia em relação à necessidade de circulação na rede de atenção. Para esses casos, os serviços devem se manter como referência para serem acessados por iniciativa do sujeito.

\section{Considerações finais}

O repertório simbólico e material concebido pela humanidade para fazer frente às fontes de sofrimento descritas acima testemunha aberturas possíveis à vida, a despeito das privações de toda ordem a que podemos estar submetidos. Em termos freudianos, se, por um lado, constata-se a impossibilidade radical de superação do estado de desamparo por meio de qualquer mecanismo, por outro, as construções culturais humanas surgem como soluções para tratar o mal-estar, mesmo que não seja possível a sua superação em definitivo.

A problematização da experiência de crise e da clínica da urgência em saúde mental não é uma tarefa fácil de ser assumida, seja por interrogar a hegemonia da psiquiatria nesse campo, seja porque tal hegemonia se alimenta da retirada voluntária e precipitada dos profissionais de outras áreas que, assustados, consideram-se tecnicamente deficitários na comparação com a eficácia atribuída ao poder psiquiátrico e seus recursos, entre os quais, em especial, o efeito concreto da medicação.

A questão de propor outra ética clínica para o acolhimento à crise e à urgência no campo da saúde mental, distinta das coordenadas do domínio biomédico, presume ter à disposição outro código e outro recurso de intervenção clínica que sejam reconhecidos e compartilhados pela pluralidade de atores que compõem esse universo e nele circulam. Nesse sentido, o campo psicanalítico dispõe de um conjunto conceitual que pode contribuir para a composição e para a invenção de práticas de cuidado singulares, bem ao estilo clínico e político do projeto psicossocial brasileiro.

Segundo essa perspectiva, ao promover a escuta como recurso privilegiado na intervenção à crise, torna-se possível deslocar e problematizar a centralidade das práticas biomédicas perante os fenômenos subjetivos da atualização do desamparo. Não se trata de dispensar o saber biomédico ou suas modalidades clínicas que convivem com o cotidiano da atenção psicossocial e com ele colaboram, mas de recuperar e situar, no dia a dia dos serviços, a capacidade de elaboração simbólica da escuta e o contorno singular da ética que a sustenta.

\section{Colaboradores}

Dassoler VA (0000-0002-4581-7415)* e Palombini AL (0000-0002-8332-8292)* contribuíram igualmente para a elaboração do manuscrito.
*Orcid (Open Researcher and Contributor ID). 


\section{Referências}

1. Brasil. Lei n ${ }^{\circ} 10.216$, de 6 de abril de 2001. Dispõe sobre a proteção e os direitos dos portadores de transtornos mentais e redireciona o modelo assistencial em saúde mental [internet]. Diário Oficial da União. 9 Abr 2001 [acesso em 2020 set 16]. Disponível em: http://www.planalto.gov.br/ccivil_03/leis/leis_2001/ 110216.html.

2. Brasil. Ministério da Saúde. Portaria GM/MS n 336 , de 19 de fevereiro de 2002. Estabelece que os Centros de Atenção Psicossocial poderão constituir-se nas seguintes modalidades de serviços: CAPS I, CAPS II e CAPS III [internet]. Diário Oficial da União. $9 \mathrm{Fev}$ 2002 [acesso em 2020 set 16]. Disponível em: http:// www.saude.mg.gov.br/images/documentos/ Portaria_336.pdf.

3. Ribeiro JM. A Agência Nacional de Saúde Suplementar e as políticas de saúde mental direcionadas para portadores de enfermidades mentais severas. Documento Técnico da ANS: RJ; 2003.

4. Foucault M. O poder psiquiátrico. São Paulo: Martins Fontes; 2006.

5. Costa MS. Construções em torno da crise. Saberes e práticas na atenção em Saúde Mental e produção de subjetividades. Arq bras psicol. 2007: 59(1)-94-108.

6. Dunker C. Mal-estar, sofrimento e sintoma: uma psicopatologia do Brasil entre muros. São Paulo: Boitempo; 2015.

7. Houaiss A. Villar MS Dicionário Houaiss de Língua Portuguesa. Rio de Janeiro: Objetiva; 2009.

8. Bauman Z. Tempos líquidos. Rio de Janeiro: Zahar; 2007.

9. Freud S. Ed. Standard brasileira das obras psicológicas completas de Sigmund Freud. Moral sexual civilizada e doença nervosa moderna [1908]. Rio de Janeiro: Imago; 1996.

10. Freud S. Ed. Standard brasileira das obras psicológi- cas completas de Sigmund Freud. Mal-estar na cultura. [1908]. Rio de Janeiro: Imago; 1996.

11. Voltolini R. O psicanalista e a pólis. Estilos clínicos. 2018; 23(1):47-61.

12. Birman J. Mal-estar na atualidade: a psicanálise e as novas formas de subjetivação. Rio de Janeiro: Civilização Brasileira; 2005.

13. Birman J. Medicalização e sociedade: efeitos de cultura, efeitos de sujeito. In: Armando GG, Menezes LS, Vieira P, organizadoras. Medicação ou Medicalização. São Paulo: Primavera Editorial; 2014.

14. Conselho Federal de Medicina. Resolução CFM n ${ }^{\circ}$ 1451/95 de 10 de março de 1995. São Paulo: CFM. [acesso em 2020 jul 15]. Disponível em: https://sistemas.cfm.org.br/normas/visualizar/resolucoes/ BR/1995/1451.

15. Barros REM, Tung Teng C, Mari JJ. Serviços de emergência psiquiátrica e suas relações com a rede de saúde mental Brasileira. Rev. Bras. Psiquiatr. [internet]. 2010 [acesso em 2020 jul 27]; 32(supl2):S71-S77. Disponível em: http://www.scielo.br/scielo.php?script=sci arttext\&pid=S1516-44462010000600003\&lng=en. https://doi.org/10.1590/S1516-44462010000600003.

16. Sanchez E. Urgências psiquiátricas. [acesso em 2020 set 16]. Disponível em: http://www.medynet.com/usuarios/jraguilar/urgencia\%20psiquiatrica.htm 2001.

17. Rechtand M, Leal E. Notas sobre a emergência psiquiátrica. In: Cadernos do IPUB. Rio de Janeiro: IPUB-UFRJ, v. 7, n. 17, 2000. p. 92-100.

18. Campolongo D. Tiempos de la urgência em las instituiciones In: Sotelo I, organizador. Tiempos de urgencia: estrategias del sujeto, estrategias del analista. Buenos Aires: JVE Editores; 2005.

19. Dell'Acqua G, Mezzina R. Resposta à crise: estratégia e intencionalidade da intervenção no serviço psiquiátrico territorial. In: Amarante P, organizador. Archi- 
vos de saúde mental e atenção psicossocial 2. Rio de Janeiro: Nau; 2004.

20. Diaz AG. Atenção à crise em saúde mental: clínica, planejamento e gestão. [tese]. Campinas: Universidade Estadual de Campinas; 2013.

21. Lobosque AM. Debatendo alguns desafios da Reforma Psiquiátrica Brasileira. Ciênc. Saúde Colet. 2011; 16(12):4590-4592.

22. Maron G, organizador. Urgência sem emergência. 2. ed. Rio de Janeiro: Subversos; 2012.

23. Souza P. Resposta à crise: a experiência de Belo Horizonte. In: Nilo K, Morais MAB, Guimarães MBL, et al., organizadores. Política de Saúde Mental de Belo Horizonte: o cotidiano de uma utopia. Belo Horizonte: Secretaria Municipal de Saúde; 2008. p. 111-127.

24. Brasil. Ministério da Saúde. $3^{\text {a }}$ Conferência Nacional de Saúde Mental. Relatório Final. Ministério da Saúde, Brasília, DF; 2010.

25. Barros REM, Tung Teng C, Mari JJ. Serviços de emergência psiquiátrica e suas relações com a rede de saúde mental Brasileira. Rev. Bras. Psiquiatr. [internet]. 2010 [acesso em 2020 jul 27]; 32(supl2):S71-S77. Disponível em: http://www.scielo.br/scielo.php?script=sci_ arttext $\&$ pid $=$ S1516-44462010000600003\&lng=en. https://doi.org/10.1590/S1516-44462010000600003.

26. Alkimin WD, organizador Carlo Viganò: Novas Conferências. Belo Horizonte: Scriptum Livros; 2010.

27. Costa MS. Construções em torno da crise. Saberes e práticas na atenção em Saúde Mental e produção de subjetividades. Arq. bras. psicol. 2007; 59(1):94-108.
28. Maron G. Urgência sem emergência. 2. ed. Rio de Janeiro: Subversos; 2012.

29. Maron G. Psicanálise e crise: urgência, sintoma e solução. In: Machado O, Grova T, organizadores. Psicanálise na favela. Projeto Digaí-maré: a clínica dos grupos. Rio de Janeiro: Assoc. Digaí-maré; 2008. p. 36-43.

30. Knobloch F. O tempo do traumático. São Paulo: EDUC; 1998.

31. Sotelo I. DATUS: Dispositivo analítico para tratamiento de urgencias subjetivas. Buenos Aires: Grama Ediciones; 2015.

32. Giglio-Jacquemot A. Urgências e emergências em saúde: perspectivas de profissionais e usuários. Rio de Janeiro: Fiocruz; 2005.

33. Berta S. Localização da urgência subjetiva em psicanálise. A peste. 2015; 7(1):95-105.

34. Bassols M. Dispositivo analítico para tratamento de urgências subjetivas In: DATUS: Prólogo de DATUS. Buenos Aires: Grama Ediciones; 2015. [acesso em 2020 jul 14]. Disponível em: https://www.gramaediciones.com.ar/productos/datus-dispositivo-analitico-para-el-tratamiento-de-urgencias-subjetivas-ines-sotelo/.

Recebido em 28/02/2020

Aprovado em 21/09/2020

Conflito de interesses: inexistente

Suporte financeiro: não houve 